\title{
Prevalence of Emotional Disorders Among Students of University of Medical Sciences; Iran
}

\author{
Valiollah Akbari ${ }^{1}$, Abbas Hajian ${ }^{2, *}$ and Parisa Damirchi ${ }^{2}$ \\ ${ }^{I}$ Department of Psychology, University of Medical Sciences, Qom, Iran \\ ${ }^{2}$ University of Medical Sciences, Qom, Iran
}

\begin{abstract}
Background: No nation-wide data are available on mental disorders in medical students. Such information can be useful for having a proper approach to and intervention for our students' health condition.

Aim: To determine the mental health status in all of the students who study in one medical university.

Methods: After invitation of all 790 students, 688 accepted to take part in this cross sectional study. We used the 28 -items of General Health Questionnaire (GHQ-28) to evaluate mental health status.

Results: Over one third (37.8\%) of our participants had mental disorders. There was no difference between genders. Emergency medicine students had the most prevalence of mental disorders $(51.4 \%)$. The increase in the years of education was associated with that of the risk of involvement. Social dysfunction and depression were more prevalent than somatization and anxiety symptoms. Lower level of graduation was associated with higher depressive symptoms and medical students were at higher risk for social dysfunction.
\end{abstract}

Conclusion: Prevalence rates among the students of the medical university are higher in comparison with the population and needs serial evaluation plans to screen and prevent mental disorders in this part of the population.

Keywords: Medical students, mental health, prevalence.

\section{INTRODUCTION}

The World Health Organization (WHO) estimates that mental disorders will be the most global burden of disease by the year 2020 [1], and at least $25 \%$ of people have psychiatric problem during their life [2]. Knowing that this prevalence is higher -up to $57 \%$ - among medical students, makes screening programs more important [3]. In comparison, undergraduate medical students have been the most suffered group of students [4], however, data shows significant psychiatric morbidities in young physician [4]. Prognostically, early detection precludes the prolongation episodes of emotional disorders and eventually decreases social impairment more in long term [5]. The most frequently used and extended emotional disorders screening test is General Health Questionnaire (GHQ), which is now available in different versions as short as 12 items (GHQ12), and as long as 60 items (GHQ-60) [6]. We used GHQ28 as the screening apparatus. Our study was intended to determine the status of the emotional disorders of the students of one of medical university of Iran, to compare with other international data as well as to provide the planning authorities of the educational system with an estimation of the rate of mental health problems among students of the medical university.

*Address correspondence to this author at the Irandust alley, Abuzar Blvd, Piruzi Street, Tehran, Iran; Tel: +989121302268;

E-mail: abbashajian@ymail.com

\section{METHODS}

Our study was a descriptive cross sectional one, done in 2011 spring. Our sample consisted of students of different fields of medical sciences including medicine, nursing, midwifery, environmental, professional, public health and some others, aging 18 and above.

All of 790 students of the university in the academic year of 2011-2012 were invited to participate in the study. A hundred and two students refused to take part and the remaining 688 answered the questionnaire completely. Two hundred and twenty two (32.7\%) were male and the rest 463 $(67.2 \%)$ were female.

We used the 28-item General Health Questionnaire (GHQ-28) as our screening test to detect mental disorders. This questionnaire was first developed by Goldberg and Hillier (1979) for screening anxiety and insomnia, social dysfunction, depression, and somatic symptoms. It scored according to the Likert scale, and its validity and reliability are both up to $91 \%$ [7, 8]. This questionnaire was translated into Farsi (the official language of Iran) and it was validated in the year of 1999 by Noorbala et al. [9]. We used traditional scoring for each section of questionnaire by considering a cut-off score of 6 , which means those who scored 6 and above had probable mental disorders. Our questionnaire contains personal demographic items including age, sex, marriage status, field of education, year of 
education, and current province to which he/she had to travel.

Data analyzed using the SPSS software. First, monovariable analysis performed for qualitative and quantitative variables. We analyzed the absolute and relative dispersion of the qualitative variables and central index for quantitative variables. In order to detect the relationship between independent and dependent variables; we used Fisher Exact Test. We considered $\mathrm{p}<0.05$ as significant value.

\section{RESULTS}

About $37.8 \%$ of students in our study had mental disorders based on GHQ-28 scores. The prevalence was $37.3 \%$ in males and $38 \%$ in females, without any significant difference between the two groups $(p=0.933)$. Although, there was no significant difference between mental disorders and some other personal demographic variables including marriage status $(\mathrm{p}=0.059)$, distance from home to university $(p>0.05)$ and to be native or not $(p=0.061)$. However, we found significant relationship between mental disorders and field of education $(\mathrm{p}=0.015)$ and also term of education course $(p=0.012)$. Table 1 shows these variables. In this study, we found a relationship between field of education and social dysfunction based on Chi-square Test. Medicine was the most accused field for social dysfunction with the prevalence of $76.1 \%(\mathrm{p}=0.018)$. We also found a significant relationship between depression and students of emergency medicine, with the prevalence of $35.1 \%(\mathrm{p}=0.01)$. However, based on the level of graduation, associate students were the most depressed ones with the prevalence of $28 \%(\mathrm{p}=0.013)$. Table 2 shows data about the prevalence of social dysfunction and depression in our study. According to analysis of our data, we concluded:

A. There was no difference in the risk of mental disorders involvement between females and males.

B. The risk of mental disorders increases with longer course of education.

C. The risk of mental disorders was related to field of education (Emergency medicine with prevalence of

Table 1. Prevalence of mental disorders in term of educational variables and genders $(\mathrm{n}=688)$.

\begin{tabular}{|c|c|c|c|c|}
\hline Variable & Sample Size(n) & Suspected Cases(n)* & Prevalence Rate(\%) & p-value \\
\hline \multicolumn{5}{|l|}{ Gender } \\
\hline Males & 225 & 84 & 37.3 & $>0.05$ \\
\hline Females & 463 & 176 & 38.0 & --- \\
\hline \multicolumn{5}{|c|}{ Field of education } \\
\hline Medicine & 138 & 62 & 44.9 & $>0.05$ \\
\hline Nursing & 143 & 59 & 41.3 & $>0.05$ \\
\hline Midwifery & 57 & 18 & 31.6 & $>0.05$ \\
\hline Environmental Health & 64 & 26 & 40.6 & $>0.05$ \\
\hline Professional Health & 41 & 15 & 36.6 & $>0.05$ \\
\hline Public Health & 49 & 18 & 36.7 & $>0.05$ \\
\hline Anesthesia & 48 & 8 & 16.7 & $>0.05$ \\
\hline Operating Room & 69 & 25 & 36.2 & $>0.05$ \\
\hline Medical Laboratory & 42 & 10 & 23.8 & $>0.05$ \\
\hline Emergency Medicine & 37 & 19 & 51.4 & 0.015 \\
\hline \multicolumn{5}{|c|}{ Term of education course } \\
\hline One & 182 & 59 & 32.4 & $>0.05$ \\
\hline Two & 146 & 55 & 37.7 & $>0.05$ \\
\hline Three & 71 & 28 & 39.4 & $>0.05$ \\
\hline Four & 98 & 35 & 35.7 & $>0.05$ \\
\hline Five & 39 & 10 & 25.6 & $>0.05$ \\
\hline Six & 65 & 35 & 53.8 & $>0.05$ \\
\hline Eight & 39 & 11 & 28.2 & $>0.05$ \\
\hline Ten & 12 & 6 & 50.0 & $>0.05$ \\
\hline Twelve & 14 & 9 & 64.3 & 0.012 \\
\hline Fourteen & 22 & 12 & 54.5 & $>0.05$ \\
\hline Total & 688 & 260 & $\mathbf{3 7 . 7 7}$ & \\
\hline
\end{tabular}

* Suspected cases: who had GHQ-28 scores of 23 or higher. 
$51.4 \%$ was on top of the list).

D. There was no relation between marriage status and/or not to be native and mental disorders.

E. Medicine itself was a high risk field for social dysfunction.

F. The most depressed students found in emergency medicine and/or associates.

\section{DISCUSSION}

Our survey shows an increase in the prevalence of mental disorders among students (37.8\%) in comparison with general population $(11.9 \%-23.8 \%)$ in Iran [10], based on GHQ-28 results. This finding is compatible with other domestic studies in different universities of Iran, which stated the prevalence of mental disorders were $12.5 \%$ to $30.4 \%$. Our findings show most of the prevalence of mental disorders in emergency medicine and medical students. The prevalence of mental disorders in medical students was compatible with a Malaysian study [6]. It may be due to more physical and emotional stress or to the longer course of education in this field.

There was no significant difference between males and females in terms of mental disorders in our study (37.3\% and $38 \%$ respectively). It is compatible with a Malaysian [6] and not compatible with other studies [11-15], which all showed higher prevalence in females than in males. This difference may be due to age, sample size and sampling methods, as the prevalence rates of mental disorders increased with age in Noorbala et al. [16], and without any correlation in Modebber-Nia et al. [14].
The study revealed significant correlation between higher term of education and mental disorder involvement. We found medical students of the Year 6 had the highest prevalence of mental disorders (64.3\%). However, in the Malaysian study [6], the fourth year and then first year students had the highest prevalence $(48.7 \%$ and $48.6 \%$ respectively). These findings are incompatible with those in the Malaysian one [6], given no significant correlation between emotional disorders and year of study in medical schools. This difference may be due to field of education, prolonged medical course, sense of futility and low selfesteem in medical students in comparison with other fields.

According to our data, social dysfunction $(65.5 \%)$ and depression $(23.1 \%)$ had the most and least prevalent symptoms among participants, respectively.

We found medical students had the most impairment of social function $(76.1 \%)$ and an independent direct correlation between this symptom and medicine was found $(\mathrm{p}=0.013)$. However, other fields also had relatively high rates of social dysfunction $(52.1 \%$ to $73.8 \%)$. We also found strong correlation between level of graduation and social dysfunction. Medicine at the doctoral level was the chief accused field $(\mathrm{p}=0.013)$. We could not find any international study to evaluate this type of correlation. This finding may be for this reason that medical students were in longer seclusion in order to read their substantial amount of readings, prolongation of their course and the nature of the field in terms of the amount of teamwork.

The total prevalence of depression was $23.1 \%$ in our study. Students of emergency medicine were the most suffered group $(\mathrm{p}=0.024)$, while the students of medical laboratory had the lowest prevalence of depression $(9.5 \%)$.

Table 2. Prevalence of social dysfunction and depression in term of educational variables $(\mathbf{n}=688)$.

\begin{tabular}{|c|c|c|c|c|c|c|c|}
\hline Variable & $\begin{array}{l}\text { Sample } \\
\text { Size(n) }\end{array}$ & $\begin{array}{c}\text { Social Dysfunction } \\
\text { Suspected Cases(n)* }\end{array}$ & $\begin{array}{c}\text { Prevalence } \\
\text { Rate(\%) }\end{array}$ & p-value & $\begin{array}{c}\text { Depression } \\
\text { Suspected Cases(n)* }\end{array}$ & $\begin{array}{c}\text { Prevalence } \\
\text { Rate(\%) }\end{array}$ & p-value \\
\hline \multicolumn{8}{|c|}{ Field of education } \\
\hline Medicine & 138 & 105 & 76.1 & 0.013 & 20 & 14.5 & $>0.05$ \\
\hline Nursing & 143 & 83 & 58.0 & $>0.05$ & 47 & 32.9 & $>0.05$ \\
\hline Professional Health & 41 & 26 & 63.4 & $>0.05$ & 8 & 19.5 & $>0.05$ \\
\hline Public Health & 49 & 35 & 71.4 & $>0.05$ & 9 & 18.4 & $>0.05$ \\
\hline Anesthesia & 48 & 25 & 52.1 & $>0.05$ & 7 & 14.5 & $>0.05$ \\
\hline Operating Room & 69 & 45 & 65.2 & $>0.05$ & 21 & 30.4 & $>0.05$ \\
\hline \multicolumn{8}{|c|}{ Degree of graduation } \\
\hline Professional doctorate+ & 138 & 105 & 76.1 & $>0.05$ & 20 & 14.5 & $>0.05$ \\
\hline Bachelor's & 500 & 316 & 63.2 & $>0.05$ & 125 & 25.0 & $>0.05$ \\
\hline Associate's & 50 & 30 & 60.0 & $>0.05$ & 14 & 28.0 & 0.024 \\
\hline Total & 688 & 451 & 65.55 & & 159 & 23.11 & \\
\hline
\end{tabular}

*Suspected cases: who had scores of 6 or higher ${ }^{+}$Professional doctorate: Medical doctors. 
Associates, according to our data, were the depressed students in comparison with those who study for higher degrees $(\mathrm{p}=0.024)$. This finding is relatively compatible with Schwenk et al. [17], regarding increased risk of new episode of emotional disorders in lower degrees of graduation, although they did not find any significant correlation. This difference in significance may be due to the sample size and evaluated fields, and other demographic factors influence the mental status of students. We found in our study the significant correlation between depression and somatic symptoms, especially in students of the third year of education ( $\mathrm{p}=0.028$ ). This finding is incompatible with those reported by the Malaysian one [6] that noted no significant correlation between year of study and emotional disorders. Our finding also is incompatible with the Malaysian one [6] which reported that depression, anxiety or both were the most prevalent symptoms of the suffering students in the U.K (40\%), and that stated in other study [18], with 5 to 20 percent of prevalence of depression in primary care centers. These differences may be due to sample size, total time at table alone for study annually, using medications, personal mood at the time of filling questionnaires and other demographic features.

\section{LIMITATIONS}

Evaluation of the sections of GHQ-28 at one section of time and by specific students could affect the answers. Given this, the results may not be generalized to the population and the students of other fields of education. From one hand, the study have done among just one medical university students and not involved the other similar ones in country, on the other hand the idea of individualized familial, cultural, economic and other social effects on level of the general health on each participant did not mind. Due to these causes we could not generalized our findings to whole country medical sciences students. As the natural type of study, this study is just useful with future similar or other synchronous regional findings to compare.

\section{CONCLUSION}

Based on our data, over one third of students are at risk of mental disorders. Moreover, mental disorders of students in the fields of medical sciences may have worsened public health conditions, because of their affect and character in public health management. We recommend doing a serial evaluation of physical and mental health, and having preventive and/or therapeutic approaches to this special group of population.

\section{CONFLICT OF INTEREST}

The authors confirm that this article content has no conflict of interest.

\section{ACKNOWLEDGMENTS}

We kindly thank the Department of Psychology of University of Medical Sciences of Qom observing all sequences of this study.

\section{REFERENCES}

[1] Murray CJ, Lopez AD. Evidence-based health policy--lessons from the Global Burden of Disease Study. Science 1996; 274: 740-3.

[2] Mohammadi MR, Davidan H, Noorbala AA, et al. Epidemiology of psychiatric disorders in Iran in 2001. Hakim J 2003; 6: 64-5.

[3] Prevalence of mental disorders. The world Mental Health survey Initiative $8^{\text {th }}$ March 2011. Available from: http://en.Wikipedia.org/ Wiki/prevalence_of_mental_disorders

[4] Noorbala AA, Mohammad K, Bagheri-Yazdi SA. Epidemiological survey of psychiatric disorders in Tehran. Hakim J 2001; 2: 212-23.

[5] Varma SL, Azhar MZ. Psychiatric symptomatology in a primary health setting in Malaysia. Med J Malaysia 1995; 50(1): 11-6.

[6] Mohd SS, Rampal L. Prevalence of emotional disorders among medical students in a Malaysian university. Asia Pac Family Med 2003; 2 : 213-7.

[7] Noorbala AA, Bagheri-Yazdi SA, Yasamy MT, Mohammadi K. A look at the mental health feature in Iran. $1^{\text {st }}$ ed. Iran: Moallef 2001; 55.

[8] Palahang H, Shah MD, Eds. Assessment of reliability and validity of GHQ-28. Iran: Tehran University of Medical Sciences 1996.

[9] Noorbala AA, Mohammad K, Bagheri YSA, et al. Validation of GHQ-28 in Iran. Hakim Mag 1999; 5: 101-10.

[10] Noorbala AA, Mohammad K, Yasamy MT, et al. A view of mental health in Iran. Tehran: Iranian Red Crescent Society Publications 2001.

[11] Boardman AP. The General Health Questionnaire and the detection of emotional disorder by general practitioner. Br J Psychiatry 1987; 151: 373-81.

[12] Vasque-Barquero JL, Garcia JS, Jesus AI, et al. Mental health in primary care: an epidemiological study of morbidity and use of health resources. Br J Psychiatr 1977; 170: 529-35.

[13] Noorbala AA, Mohammad K, Bagheri YSA. A survey of psychiatric disorders in Tehran city. Hakim Mag 1998; 4: 212-23.

[14] Modabber-Nia MJ, Tehrani H. The prevalence of depression among high school and pre-university Adolescents: Rasht, Northern Iran. Arch Iranian Med 2007; 10(2): 141-6.

[15] Finlay-Jones RA, Burvill PW. The prevalence of minor psychiatric morbidity in the community. Psychol Med 1971; 7: 475-89.

[16] Noorbala AA, Mohammad K, Bagheri YSA. Mental health survey of the adult population in Iran. BJP 2004; 184: 70-3.

[17] Schwenk T, Davis L, Wimsatt L. Depression, stigma, and suicidal ideationin medical students. JAMA 2010; 304(11): 1181-90.

[18] Lasebikan V, Ejidokun A, Coker A. Prevalence of mental disorders and profile of disablement among primary health care service users in Lagos island; Epidemiology Research International: Vol. 2012, Article ID 357348, 6 pages. 